\title{
Mathematical Optimization Model for Truck Scheduling in a Distribution Center with a Mixed Service-Mode Dock Area
}

\author{
Gustavo Correa Issi, ${ }^{1}$ Rodrigo Linfati $\mathbb{D}^{2},{ }^{2}$ and John Willmer Escobar ${ }^{3}{ }^{3}$ \\ ${ }^{1}$ School of Industrial Engineering, University of Bío-Bío, Concepción 4030000, Chile \\ ${ }^{2}$ Department of Industrial Engineering, University of Bío-Bío, Concepción 4030000, Chile \\ ${ }^{3}$ Department of Accounting and Finance, Universidad del Valle, Cali 760001, Colombia \\ Correspondence should be addressed to John Willmer Escobar; john.wilmer.escobar@correounivalle.edu.co
}

Received 7 July 2020; Revised 12 November 2020; Accepted 17 November 2020; Published 27 November 2020

Academic Editor: David Rey

Copyright ( $\odot 2020$ Gustavo Correa Issi et al. This is an open access article distributed under the Creative Commons Attribution License, which permits unrestricted use, distribution, and reproduction in any medium, provided the original work is properly cited.

\begin{abstract}
Cross-docking is a logistics strategy in which products arriving at a distribution center are unloaded from inbound trucks and sorted for transfer directly to outbound trucks, reducing costs and storage and product handling times. This paper addresses a cross-docking problem by designing a mixed-integer linear programming (MILP) model to determine a schedule for inbound and outbound trucks in a mixed service-mode dock area that minimizes the time from when the first inbound truck arrives until the last outbound truck departs (makespan). The model is developed using AMPL software with the CPLEX and Gurobi solvers, which provide results for different instances, most of these with actual shift data from an integrated distribution center of a multinational food company located in Concepción, Chile. The results obtained from the case study are notable and show the effectiveness of the proposed mathematical model.
\end{abstract}

\section{Introduction}

In a traditional distribution center, products are received and then stored. When a customer requests a product, workers take it from storage and send it to the destination in four main operations: receiving, storage, order picking, and shipping [1]. Storage and order picking are usually the costliest processes since inventory maintenance costs, plus the use of labor, are included [2]. One approach to reducing costs could be adopting a cross-docking system, eliminating storage and order picking operations [3]. Crossdocking is a logistics strategy used by many companies throughout the world. Cross-docking consists of transferring the flow of products directly to outbound vehicles without storing the products, which in practice helps to consolidate shipments, reduce delivery times, and reduce storage costs [4, 5]; Mavi et al. [6]. Nasiri et al. [7] present a MILP model incorporating supplier selection and order allocation into the VRPCD in a multi-cross-dock system minimizing the total costs, including purchasing, transportation, cross-docking, inventory, and early/tardy delivery penalty costs.

Cross-docking requires correct synchronization of inbound and outbound vehicles; however, perfect synchronization is difficult to achieve in practice because incoming products must, at least, be sorted, consolidated, and stored until complete outbound shipment. Indeed, cross-docking can be defined as the process of consolidating freight with the same destination (coming from several origins), with minimal handling and with little or no storage [8]. If the products are temporarily stored, this should only be for a short time. An exact limit is difficult to define, but many authors speak of no more than 24 hours [9]. Otherwise, if the products are placed in a warehouse or on shelves to prepare orders and wait for several days or even weeks in storage before being dispatched, it is not considered crossdocking but as traditional storage. Many organizations use a combination of warehousing and cross-docking to reap both approaches [10]. Arbabi et al. [11] developed a hub-andspoke architecture for a parcel delivery system using a 
network that includes a distribution center and several crossdock facilities. Several real-world assumptions, including an electric truck fleet, mobile charging station, third-party logistics, capacity constraints, last-mile deliveries, and customer dissatisfaction, are incorporated in this problem. A combined algorithm based on the fix-and-relax algorithm (FARA) and genetic algorithm (GA), namely, Mb-FARGA, is proposed to solve the problem.

In the cross-docking studies, various types of decisions can be classified and differentiated. The types of decisions are strategic (long-term) and operational (short-term) [9, 12]. Long-term decisions consider the location of distribution centers and the best distribution of docks, in addition to establishing a network between the cross-docking center and the suppliers and customers [13]. Operational or short-term decisions involve dock assignment, truck scheduling, and temporary storage in the cross-docking center [14].

1.1. Cross-Docking Strategic Decisions. A distribution center's location is treated as one of the initial steps to install and start cross-docking processes. Bachlaus et al. [15] considered a supply chain that included suppliers, plants, distribution centers, cross-docks, and customers. The objective was to optimize the flow of materials throughout the supply chain and identify the facilities' optimal quantity and location. The problem was formulated as a multi-objective optimization model that sought to minimize total costs and maximize plant flexibility and volume. Another strategic decision that has to be made for a cross-docking platform is its design. Bartholdi \& Gue [16] studied the relationship between the system with performance and productivity. Finally, organizing the collection and delivery of products after consolidation in the cross-docking platform is called vehicle routing. This problem has been addressed by Lee et al. [17] and Liao et al. [18].

Some studies have been briefly described that analyze cross-docking strategic problems whose decisions are oriented in the long term and which, for this work, serve to contextualize the dimension of what the cross-docking system generally involves.

1.2. Cross-Docking Operational Decisions. Given that this paper has an operational focus, problems existing within cross-docking whose decisions are short term or operational and that serves as the basis for the considered problem are described below.

1.2.1. Platform Assignment. When a vehicle arrives at the dock for loading or unloading, the trucks' dock assignment needs to be chosen. This allocation could mean an increase or decrease in productivity, handling costs, or even, in extreme cases, to deliver or not order on time. For these problems, it is assumed that there are as many platforms as the number of trucks; otherwise, the problem would become a truck scheduling problem analyzed in the following section.
Dock assignment was addressed by Tsui \& Chang [19]. In their work, storage was not allowed, and therefore all products went directly to outbound trucks. The authors presented this case as a bilinear programming problem that attempted to minimize cranes' travel distance.

1.2.2. Truck Scheduling. In the truck scheduling problem, docks are scarce, and trucks compete for that resource. It is not enough to assign a specific dock to an inbound or outbound truck. Instead, it must also be decided when to process the truck. For this reason, this kind of problem often combines the dock assignment issue with some characteristics that change, such as the number of docks, manual transport (hand pallet truck, reach crane) vs. automatic transport (conveyor belts), and whether internal storage is allowed, among others. Multi-objective truck scheduling problems have been proposed by Rahbari et al. [20]. The authors propose a bi-objective MILP model for the vehicle routing and scheduling problem with cross-docking for perishable products. Two robust models have been proposed by considering the travel time of the outbound vehicles and the products' freshness-life as uncertain.

Goodarzi et al. [21] address a multi-objective vehicle routing problem with cross-docking (VRPCD), considering truck scheduling, splitting pickup, and delivery orders with a time-windows supplier and retailer locations, optimizing the cost efficiency and responsiveness. A new bi-objective mixed-integer linear programming model is presented, and a multi-objective meta-heuristic evolutionary algorithm is proposed for solving the problem. Besides, Khorshidian et al. [22] develop a bi-objective mathematical model to integrate truck scheduling and transportation planning in a crossdocking system in a forward/reverse logistics network. A hybrid of the improved version of the augmented e-constraint method and TOPSIS is used for solving the problem.

1.2.3. Stacking and Individual Platforms. Several authors consider a simplified cross-docking center with a single product stacking location and a single platform to study the truck scheduling problem. In this way, the problem is reduced to the sequence of inbound and outbound trucks.

Chen \& Lee [23] evaluated the problem called the "twomachine cross-docking flow shop problem." The objective is to sequence inbound and outbound trucks to minimize the makespan. This problem was modeled as a flow problem of two machines, with additional precedence constraints to ensure that an outbound truck was not processed before its predecessor tasks were completed. In Chen \& Song [24], this scheduling problem was extended to a two-stage hybrid cross-docking problem. The difference in the problem was that now multiple trucks could be loaded or unloaded at the same time because the machines were considered in parallel at the inbound and outbound stages.

Boysen et al. [25] considered the same type of problem with a time horizon scheme divided into discrete time intervals and assumed that trucks could be loaded or unloaded within these intervals. The problem was formulated as an integer programming model, and to solve it, a 
decomposition approach that considered two subproblems was proposed.

1.2.4. Inbound Truck Scheduling. Other papers deal with problems considering real cases, multiple platforms, and stacking places but only focus on scheduling inbound trucks. It is assumed that outbound trucks are already scheduled or assigned in a medium horizon term. In other words, the destinations of these trucks have already been previously set to the exit platforms.

Rosales et al. [26] studied inbound truck assignments at a large cross-dock facility in Georgetown, Kentucky. The assignments were scheduled during a shift period, and the goal was to minimize the operating cost by providing a balanced workload for all workers. Temporary storage was allowed in this work. The authors formulated the scheduling problem as a mixed-integer programming model that included workload balancing constraints.

Other authors consider the same problem but propose some dispatching rules applied to a dynamic environment. Wang \& Regan [27] considered several inbound trucks waiting to be unloaded when a dock was available. Usually, the next truck to arrive should follow a first-in, first-out policy as a fair wait time rule for all trucks. However, this policy could lead to a suboptimal result in a cross-dock center. Therefore, the authors proposed two algorithms based on the time associated with a new inbound truck's impact on the entire process (from when a product arrived on the inbound truck until it left on an outbound truck) or the total transfer time of products. Temporary storage is not allowed, and one truck is available for each destination. Stochastic approaches for this problem have been considered by Konur \& Golias [28]. This paper considers scheduling inbound trucks at the doors of a cross-dock facility under truck arrival time uncertainty. The authors propose a genetic algorithm (GA) to solve the truck-to-door assignments for truck arrival times, which solves the problem by considering different scenarios according to the uncertainty of parameters.

Finally, Boysen et al. [29] consider an operational truck scheduling problem, where a dock door and a start time have to be assigned to each inbound truck. A set of outbound trucks is scheduled beforehand and, therefore, departure times are fixed. Indeed, the paper introduces and formalizes a truck scheduling problem.

1.2.5. Inbound and Outbound Trucks Scheduling. The works analyzed above take on more relevance in real life when combined and cover the most significant number of characteristics and processes that occur within a distribution center or cross-docks. Therefore, many authors refer to the scheduling of inbound and outbound trucks to get closer to a cross's reality dock center. For this work, the articles described below are very relevant for the considered problem.

Boysen [30] addressed the problem of scheduling inbound and outbound trucks with a zero-inventory policy: temporary storage was not allowed since the work focused on handling food products with stringent cooling requirements without breaking the cold chain. The author presented several operational objectives, such as minimizing flow time, processing time, and delays of outbound trucks. Shakeri et al. [31] studied the problem of the exchange of products between trucks. The objective was to minimize the makespan of the problem. In that work, the process was described as follows: in the unloading stage, goods were unloaded and moved to temporary storage (assuming an infinite capacity); then, the products were loaded sequentially on the trucks. Loading the truck could only start if the truck had been fully unloaded and if all products to be loaded were ready in the storage area. The authors provided a mixed-integer programming (nonlinear) formulation of the problem used for small-scale instances. $\mathrm{Li}$ et al. [32] presented a dependency ranking search (DRS) heuristic method consisting of two parts to resolve larger problems. The first part constructed a feasible sequence of tasks concerning the number of docks, and the second part assigned those tasks to docks depending on the distances. Some computational tests showed that, for small-scale instances, the CPLEX solver performed slightly better than the DRS heuristic, but CPLEX was significantly slower. For instances of medium and large problems, CPLEX did not find feasible solutions in most cases, while the heuristic found a solution in a few minutes in more than eight of every ten instances. Enderer et al. [33] presented an integrated cross-dock-door assignment and vehicle routing problem in cross-dock terminals' operation. The problem considers the assignments of platforms to inbound trucks and the scheduling of outbound trucks to destinations. The objective is the minimization of the total material handling and transportation costs.

Thai [34] mentioned that seaports' role is essential since these transport nodes are essential and indispensable for the effective and efficient management of products and information in the supply chain. This research issue is explored through a conceptual model of competencies constructed based on a thorough literature review and in-depth interviews validated by a survey with port personnel in Singapore and Vietnam. Saranen et al. [35] studied the purpose of providing knowledge on the transportation strategies employed in international lean oriented supply chains involving developing economies. In this work, it is essential to mention that some products (e.g., after-sales, spare parts) are requested to country-level dedicated warehouses to serve customer demands.

One of the most important articles published regarding cross-docking was by Yu \& Egbelu [36]. The article's objective was to find the best "coupling sequence" or schedule for inbound and outbound trucks and minimize the total operations time or makespan. Temporary storage was permitted and occurred in front of the shipping docks. Two different solution approaches were developed to address the problem. The first approach proposed a mixed-integer programming model. In the second approach, a two-stage heuristic algorithm was developed. The first stage found the best subset of inbound trucks that were the best candidates for transferring freight to each unscheduled outbound truck. In the second stage, each unscheduled outbound 
truck and the associated inbound trucks were selected and scheduled.

$\mathrm{Yu}$ [37] proposed a method to find the best docking sequences for trucks at each receiving and shipping dock and assignments of inbound and outbound trucks to docks to minimize the cross-docking system's makespan multiple docks. The unloading sequences of products from inbound trucks, product routing, and routing sequences are also determined simultaneously. In this work, a mathematical model and two heuristic algorithms have been proposed. Stochastic approaches for the inbound and outbound truck scheduling are proposed by Heidari et al. [38]. In this paper, the problem of scheduling inbound and outbound trucks at a cross-dock facility when vehicle arrival times are unknown through a cost-stable scheduling strategy is addressed. Two meta-heuristics are used for solving the considered problem.

Recently, Rijal et al. [39] and Sayed et al. [40] have considered this research's problems. Rijal et al. [39] considered the problem of operational decisions at cross-dock facilities by including a mixed service mode when both inbound and outbound trucks can be processed at the same doors. The literature and practice often consider the truck scheduling and dock-door assignment problem sequentially or only for either inbound or outbound operations. An adaptive large neighborhood search algorithm to solve the integrated problem and find good solutions within a reasonable amount of computational effort is proposed in this work. Sayed et al. [40] addressed an integrated cross-dock door assignment and truck scheduling problem determining the assignment and scheduling of inbound trucks to inbound doors and outgoing trucks to outbound doors without considering temporal storage. The objective function is the minimization of the total time to process all trucks. Two mathematical programming formulations and two-hybrid metaheuristics are proposed to solve the problem. Finally, Guo et al. [41] proposed a parallel machine scheduling problem with job synchronization for a generic hub terminal problem synchronizing inbound and outbound flows. Two mathematical models and an efficient heuristic have been proposed for solving the considered problem.

Based on the literature review, cross-docking has been the focus of many authors who have written a significant number of papers, documents, or theses in the last twenty years. Several articles deal with cross-docking in a more general way, while other documents address a specific type of problem at either the strategic or operational level. Despite this, the same authors point out that there are still many opportunities to improve and expand the research that so far exists. For example, few articles refer to cross-docking with temporary storage; although this approach tries to eradicate all storage types, it is not so in practice. Another case that the authors rarely analyze is expanding the research by considering that the same platforms could load and unload products (mixed modality), as is the case analysis of the considered problem; few documents constrains the departure date or time limit for the outbound trucks. Most of the papers analyzed assume that the platforms are located on opposite sides, and it is not considered that these platforms could be located only in one sector of the distribution center (mixed platform area). Finally, concerning real applications, Ladier \& Alpan [42] have determined the gap between the proposed approaches to cross-docking problems and real case applications. The authors mentioned that the number of articles on the subject has been growing very fast but largely detached from industry practice. That work proposes a common framework that compares the literature review regarding cross-docking operations with on-field observations and platform managers' interviews to see whether the current state of the art matches the industry practice.

This paper proposes a mathematical model in a crossdocking environment for scheduling inbound and outbound trucks that arrive at the docks. The proposed model aims to reduce the operation time of transferring products, that is, to minimize the time from when the first inbound truck arrives to unload its products until the last outbound truck leaves with its load. This time is known as the makespan. The model is tested with actual data obtained from a multinational food company in Chile, located in Concepción, and under different scenarios. The main contribution is the consideration and integration of several approaches to find a model that fits into the reality of the cross-docking operation of the companies and, at the same time, contribute other types of considerations, such as platforms located in a single sector and of mixed modality, which has been scarcely analyzed even in cross-docking research. Similarly, the real application case results measure the solution strategy's efficiency, allowing its scalability to other companies with similar characteristics.

\section{Problem Description and Proposed Mathematical Model}

The considered problem is related to a cross-docking system and encompasses two operational procedures: reception and dispatch. The problem allows the scheduling of inbound and outbound trucks minimizing the time from when the first truck enters until the last truck leaves, known as makespan. The cross-docking system addressed in this paper works as described below.

Inbound trucks arrive at the distribution center and are assigned a platform, and all unloaded products are transferred to temporary storage with two options: front of the platforms or the racks. Then, the operators consolidate on the pallets all the products that must be dispatched in a truck. Each truck's loads are checked by a dock controller and loaded onto dispatch trucks. Once all products are loaded onto the corresponding truck, they leave the distribution center.

Inbound trucks and outbound trucks must remain on the platforms until they complete their unloading or loading processes, respectively, and must leave the platform immediately when they complete their task. All trucks are assumed to be available at the beginning of the schedule or the beginning of the shift. The proposed model considers platforms located in a single area of the distribution center and serves to load and unload products. It is assumed that the total products unloaded from the inbound trucks are 
equal to the number of products loaded on the outbound trucks; this avoids long-term storage, although temporary storage is permitted. Product transfer from inbound trucks to outbound trucks is determined by the model and dock assignments along with inbound and outbound truck sequences. The loading and unloading time for each type of product are known as well as differences between them. The truck exchange time is the time required for a truck to leave the platform and enter another truck on the same platform, and it is assumed to be the same for inbound trucks and outbound trucks.

The model's mathematical formulation proposed to solve the truck scheduling problem in a distribution center with mixed service-mode docks is explained as follows.

\subsection{Sets}

$V=$ trucks $(V=I \cup O)$

$I=$ inbound trucks.

$\mathrm{O}=$ outbound trucks.

$P=$ type of product.

$D=$ number of mixed docks.

$S=$ number of temporary storage locations.

\subsection{Parameters}

$f_{\mathrm{vp}}=$ number of units of product type $p$ that are unloaded (inbound) or loaded (outbound) from truck $v$.
$\mathrm{PU}_{p}=$ unloading time of product $p$.

$\mathrm{PL}_{p}=$ loading time of product $p$.

$Q_{s k}=$ capacity of temporary storage location $s$ that is in front of dock $k$.

$W_{k k^{\prime}}=$ travel time of the products from dock $k$ to dock $k^{\prime}\left(k \neq k^{\prime}\right)$, through storage location $s=1$.

TS $=$ travel time of the products from temporary storage location $s=2$ to the outbound truck.

$\mathrm{TE}=$ truck exchange time.

$M=$ a large positive number.

$l_{j}=$ latest departure time for outbound truck $j$.

\subsection{Decision Variables}

\subsubsection{Continuous Variables}

$T=$ "makespan" or total operation time.

$a_{v}=$ arrival time of truck $v$ at the dock.

$d_{v}=$ departure time of truck $v$ at the dock.

\subsubsection{Discrete Variables}

$x_{i j p s}=$ number of units of product type $p$ that are transferred from inbound truck $i$ to outbound truck $j$, through temporary storage location $s$.

\subsubsection{Binary Variables.}

$v_{i j s}= \begin{cases}1, & \text { if any product is transferred from inbound truck into outbound truck } j \text { through temporary storage } s, \\ 0, & \text { Otherwise. }\end{cases}$

$p_{i j k}= \begin{cases}1, & \text { if truck } i \text { precedes truck } j \text { in the sequence of inbound trucks, at dock } k, \\ 0, & \text { Otherwise. }\end{cases}$

$q_{i j k}= \begin{cases}1, & \text { if truck } i \text { precedes truck } j \text { in the sequence of outbound trucks, at dock } k, \\ 0, & \text { Otherwise. }\end{cases}$

$y_{i k}= \begin{cases}1, & \text { if inbound truck } i \text { is assigned to dock } k, \\ 0, & \text { Otherwise. }\end{cases}$

$z_{j k}= \begin{cases}1, & \text { if outbound truck } j \text { is assigned to dock } k, \\ 0, & \text { Otherwise. }\end{cases}$

\subsection{Objective Function}

Minimize: $T$.

\subsection{Constraints.}

$$
\begin{gathered}
T \geq d_{j}, \quad \forall j \in O, \\
\sum_{s=1}^{|S|} \sum_{j=1}^{|O|} x_{i j p s}=f_{i p}, \quad \forall i \in I ; \forall p \in P,
\end{gathered}
$$

$$
\begin{gathered}
\sum_{s=1}^{|S|} \sum_{i=1}^{|I|} x_{i j p s}=f_{j p}, \quad \forall j \in O, \forall p \in P, \\
x_{i j p s} \leq M * v_{i j s}, \quad \forall i \in I ; \forall j \in O ; \forall p \in P ; \forall s \in S,
\end{gathered}
$$




$$
\begin{aligned}
& \sum_{j=1}^{|O|} \sum_{p=1}^{|P|} x_{i j p s} \leq Q_{s k}, \quad \forall i \in I ; \forall s \in S ; \forall i \in I \\
& d_{i} \geq a_{i}+\sum_{p=1}^{|P|} f_{i p} * \mathrm{PU}_{p}, \quad \forall i \in I \\
& d_{j} \geq a_{j}+\sum_{p=1}^{|P|} f_{j p} * \mathrm{PL}_{p}, \quad \forall j \in O, \\
& d_{j} \leq l_{j}, \quad \forall j \in O, \\
& a_{j} \geq d_{i}+\mathrm{TE}-M *\left(1-\sum_{k=1}^{|D|} p_{i j k}\right), \quad \forall i, j \in I ; i \neq j \\
& a_{j} \geq d_{i}+\mathrm{TE}-M *\left(1-\sum_{k=1}^{|D|} q_{i j k}\right), \quad \forall i, j \in O ; i \neq j, \\
& a_{j} \geq a_{i}+\mathrm{TE}-M *\left(2-y_{i k}-z_{j k}\right), \quad \forall i \in I ; \forall j \in O ; \forall k \in K, \\
& a_{j}+M *\left(3-v_{i j 1}-y_{i k}-z_{j k}\right) \geq d_{i}+\sum_{p=1}^{|P|} x_{i j p 1} * W_{k k^{\prime}}, \\
& \forall i \in I ; \forall j \in O ; \forall k, k^{\prime} \in D \text {, } \\
& a_{j}+M *\left(1-v_{i j 2}\right) \geq d_{i}+\sum_{p=1}^{|P|} x_{i j p 2} * \mathrm{TS}, \quad \forall i \in I ; \forall j \in O, \\
& \sum_{k=1}^{|D|} y_{i k}=1, \quad \forall i \in I \\
& \sum_{k=1}^{|D|} z_{j k}=1, \quad \forall j \in O \\
& p_{i j k}+p_{j i k} \leq 1, \quad \forall i, j \in I ; i \neq j \forall k \in D, \\
& q_{i j k}+q_{j i k} \leq 1, \quad \forall i, j \in O ; i \neq j \forall k \in D, \\
& p_{i j k}+p_{j i k} \geq y_{i k}+y_{j k}-1, \quad \forall i, j \in I ; i>j \forall k \in D, \\
& q_{i j k}+q_{j i k} \geq z_{i k}+z_{j k}-1, \quad \forall i, j \in O ; i>j \forall k \in D, \\
& T, c, F, d, L \geq 0, x \in Z^{+} \cup\{0\}, v, p, q, y, z \in\{0,1\} .
\end{aligned}
$$

Constraints (2) establish a makespan greater than or equal to the time the last scheduled outbound truck departs the dock. Constraints (3) ensure the number of units of product type $p$ transferred from inbound truck $i$ to all outbound trucks through all temporary storage locations is equal to the number of units of product type $p$ originally unloaded from inbound truck $i$. Similarly, the set of constraints (4) ensures that the number of units of product type $p$ transferred from all inbound trucks to outbound truck $j$, through all temporary storage locations, equals the number of units of product $p$ loaded on outbound truck $j$. Constraint (5) forces the correct relationship between integer variable $x_{i j p s}$ and binary variable $v_{i j s}$; it establishes that when at least one product of type $p$ is transferred from an inbound to an outbound truck through temporary storage location $s$, the integer variable has a positive value and the binary variable equals 1. Constraint (6) complements constraint (5) and establishes that when there is no transfer ( 0 products are transferred), variable $v_{i j s}$ does not take the value of 1 because we assume there are 0 products transferred. Constraint (7) establishes that the total number of products transferred from all inbound trucks to outbound truck $j$ through temporary storage location $s$ does not exceed the capacity of temporary storage location $s$ that is in front of the dock where truck $j$ is. Similarly, constraint (8) establishes that the total number of products transferred from inbound truck $i$ to all outbound trucks, through temporary storage location $s$, does not exceed the capacity of temporary storage location $s$ that is in front of the dock where truck $i$ is. In short, the above constraints ensure that the quantity of products unloaded or loaded at a single dock does not exceed the capacity of the temporary storage location.

Constraint (9) establishes that the departure time of inbound truck $i$ is greater than or equal to the arrival time of the same truck plus the time to unload all products. This constraint also ensures that the inbound truck departs the dock once all its products are unloaded. Constraint (10) is similar to that one but for outbound trucks: it establishes that the departure time of outbound truck $j$ is greater than or equal to the arrival time of that truck plus the time to load its freight. This constraint also ensures outbound truck $j$ only leaves after all its products are loaded. Constraint (11) establishes that the departure time of outbound truck $j$ should also be less than or equal to the latest departure time set previously.

Constraint (12) establishes a valid sequence for inbound trucks. In the event an inbound truck $i$ precedes inbound truck $j$ at the same dock $k$, the arrival time of truck $j$ will be greater than or equal to the departure time of truck $i$ plus the time it takes to exchange trucks. Constraint (13) establishes the same relationship but for outbound trucks. In the event that inbound and outbound trucks are assigned to the same dock, constraint (14) ensures that if outbound truck $j$ is assigned to dock $k$, where inbound truck $i$ is parked, the arrival time of outbound truck $j$ will be greater than or equal to the time when inbound truck $i$ departs the dock plus the truck exchange time.

Constraint (15) establishes that if products are transferred from inbound truck $i$ to outbound truck $j$ through temporary storage location $s=1$, and truck $i$ is at dock $k$ and truck $j$ is at dock $k^{\prime}$, then the arrival time of outbound truck $j$ will be greater than or equal to the departure time of inbound truck $i$ plus the transfer time of all products from dock $k$ to $k^{\prime}$. If both trucks are at the same dock, this transfer 
time is 0 . Constraint (16) establishes that if products are transferred from inbound truck $i$ to outbound truck $j$ through temporary storage location $s=2$, the arrival time of outbound truck $j$ will be greater than or equal to the departure time of inbound truck $i$ plus the time to move the products from temporary storage location $s=2$ to outbound truck $j$. With constraints (14)-(16), it is established that inbound trucks arrive before outbound trucks. Constraints (17) and (18) ensure that each inbound truck and each outbound truck, respectively, are only assigned to one dock.

Constraint (19) ensures that if inbound truck $i$ precedes inbound truck $j$, then inbound truck $j$ cannot precede truck $i$. Constraint (20) establishes the same relationship but for outbound trucks. Constraints (21) and (22) complement constraints (19) and (20), respectively. Constraint (21) establishes that if two inbound trucks are assigned to the same dock, then only one of them may precede the other. Constraint (22) does the same for outbound trucks. Finally, constraint (23) defines the types of decision variables considered in the model.

\section{Results}

3.1. Case Study. The proposed approach has been tested with actual data obtained from a multinational food company in Chile, located in the Bio-Bio region. Currently, the integrated distribution center (IDC) of the company supplies supermarket chains such as Walmart, SMU (Unimarc, Mayorista 10), and Cencosud, which are its wholesale customers, and other customers that are its retail-type customers (businesses, grocery stores, minimarkets, etc.). The products distributed are divided into four categories: Traditional or Food, Beverages, and Dairy (FBD), including products such as coffee, breakfast cereals, milk, candy, and culinary products. The Ice Cream category is for brand products Savory and Chamonix. The Refrigerated category is for yogurts and desserts. The Pet Care category is for pet food, including brands like Purina, Dog-Chow, and Doko. It is found that the supply and distribution trucks arrive at the IDC arbitrarily within the operational processes. Therefore, it is necessary to establish a schedule for the supply and dispatch trucks to reduce the trucks' loading and unloading time windows.

Since this is the only distribution center in Chile that works with four product categories in which each has different brands and, in each brand, there are other formats, it is complex to manage tasks in an eight-hour shift, such as receiving, classifying, storing, and shipping a variety of orders to customers. For that reason, one of the problems identified in high-demand months, such as December, is that overtime work is quadruple that of low-demand months, such as March. This excess of overtime is mainly due to inadequate coordination between internal warehouse operations and inbound trucks, which arrive arbitrarily at the IDC without any schedule or timetable.

This truck scheduling deficiency also causes delay fees due to the inability to unload certain inbound trucks when these arrive at the IDC. These situations occur daily, and the company has to send inbound trucks "on tour"; that is, the truck has to wait somewhere else because there is not enough space in the maneuvering area, and the 11 docks that are busy otherwise cannot be used for work operations. A similar situation is when outbound trucks must wait in the maneuvering area because the products of their routes are not ready to be loaded or when orders ready to be shipped occupy space in the loading area because the truck assigned to deliver those orders has not arrived at the IDC.

Many of these scenarios that involve inbound and outbound trucks occur because the docks are located in one area of the warehouse and are used for loading and unloading trucks (mixed service mode), unlike most distribution centers analyzed in the literature, which have docks exclusively dedicated to loading and others dedicated to unloading and are usually "I"-shaped and located on opposite sides of the warehouse [16].

The IDC currently has two exclusive docks for loading and unloading Ice Cream products (docks 1 and 2, see Figure 1) and a dock exclusively for Refrigerated and RCC products (Refrigerated products that are dispatched to others customers different from supermarkets) (dock 3). However, there is the flexibility to use a dock for Ice Cream to load Refrigerated products and vice versa. The FBD warehouse has six docks (docks 4 through 9) that are exclusively for loading and unloading Traditional or FBD products and Beverage and Pet Care products. For a future scenario in which a new Ice Cream chamber will be operational (area in green of Figure 1), tests are being run where there are three exclusive docks for Refrigerated and RCC products (docks 1 through 3 ) and two exclusive docks for Ice Cream products (docks 10 and 11).

3.2. Obtained Results. This section presents the proposed model results and evaluates real scenarios in the IDC's operational shifts. Besides, since there are no studies that resemble the IDC characteristics, exploratory factor analysis is carried out to validate whether the model delivers, within a reasonable time, feasible results of the makespan's behavior when its parameters change. Mainly, one parameter value is changed at a time while the others remain constant. For the exploratory factor analysis, four parameters are evaluated: inbound trucks $(|I|)$, outbound trucks $(|O|)$, number of products $(|P|)$, and number of docks $(|D|)$. The instances were solved by setting three of the four parameters with a value of 5 . The other parameter takes values between 1 and 21 to carry out the experimental analysis and test the proposed model's efficiency. For example, for the first execution, $|I|,|O|$, and $|P|$ are set to 5 , and $|D|$ varies from 1 to 21 . For the subsequent execution, $|I|,|O|$, and $|D|$ are set to 5 , and $|P|$ ranges from 1 to 21 , and so on. Finally, the best results are chosen.

Maximum runtime of 9000 seconds (2.5 hours) is established to obtain the results presented in this chapter. All instances are run using the mathematical modeling software AMPL (version 20180308), and the results obtained are compared to those of the CPLEX and Gurobi solvers on a computer with Intel Xeon CPU processor E5-2660, 48 GB RAM, and the Red Hat Enterprise Linux 7 operating system. 

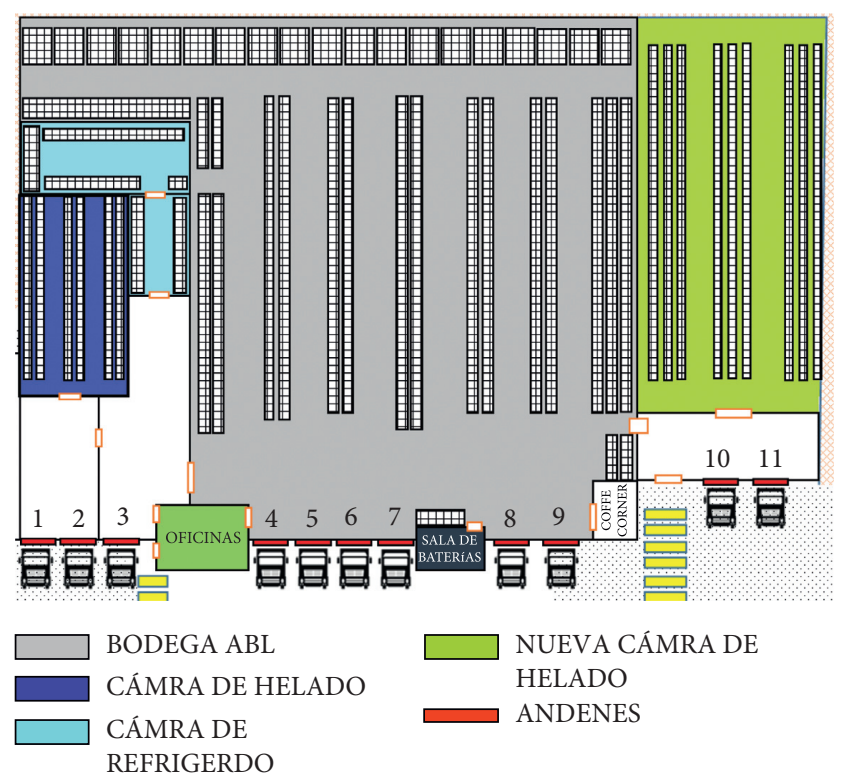

FIgUre 1: Structural warehouse layout, Concepción IDC, section: operations warehouse (source: emergency layout, Concepción IDC).

Extensive tests were performed on three rotating shifts of operation of the IDC. Similarly, tests were run for the current scenario and a future scenario where the number of trucks changes in some cases and the number of docks changes in other cases. Tests were done for B shift, which runs between 15 : 00 and $23: 00$. In the first test, three inbound trucks arrive and 15 trucks are dispatched. In the second test, four trucks arrive, and 17 are dispatched. The types of products handled are FBD, Beverages, and Pet Care. Both tests were done to determine how many docks are needed to obtain a schedule with minimal makespan. For $\mathrm{C}$ shift, which is between $23: 00$ and $07: 00$, two tests were also performed, although this time the number of available docks changes because, in a future scenario, the Ice Cream chamber moves to a different area in the warehouse and frees the current Ice Cream chamber for increased capacity of the Refrigeration chamber. In each category, one inbound truck arrives. In the Ice Cream category, 19 trucks are dispatched, and in the Refrigerated category, 17 trucks are dispatched, of which 12 go to wholesale customers such as supermarkets and five to retail customers (RCC).

3.2.1. Factor Analysis. Once all tests with the variation of each parameter have been analyzed, it can be said that, in general, the model delivers optimal solutions in a few seconds when parameter values remain close to each other, for example, four inbound trucks, six outbound trucks, and five docks. These three parameters $(I, O, D)$ have the most influence on makespan; the number of types of products $(|P|)$ is negligible since it will depend on each product's characteristics and not on how many types are being handled. However, when loading and/or unloading times are different between the types of products $(|P|)$, it is not recommended to load more than three different types of products on the same truck since that would cause significant makespan variation.

Therefore, a minimum makespan is obtained when products are distributed equally in the fewest possible trucks, both inbound and outbound, and consequently, the consolidation of products in few trucks must be prioritized over the diversification of products in many trucks. The makespan will also decrease as the number of docks increases, but after the minimum time required for the operation with a certain number of docks is reached, or if there is a critical route in the schedule, the makespan will have the minimum value obtained above or the value of the critical route, and it will keep that value even if the number of docks is increased.

3.2.2. B Shift Results. For the current state, the minimum makespan with one and two docks available exceeds the duration of a shift (420 minutes), so this is not a feasible solution. With three docks available, a feasible solution of 338 minutes is obtained. This solution is not optimal since both solvers require the maximum run time of 9000 seconds to obtain this makespan, as it did for the two previous cases. Changing from three to four docks causes a makespan decrease of 68.9 minutes.

When four, five, or six docks are available, a minimum makespan of 269.1 minutes is obtained. Thus, multiple optimal solutions can be found with more docks available. This fact seems to suggest that workflows with four, five, and six docks are equal but based on what is seen in each schedule and the opinion of experts, the best would be to schedule trucks with five docks; this allows for a larger slack time between trucks than scheduling four docks. This slack time between trucks' exchange could be two or three times the current slack time, set at 10 minutes. This fact would result in a more flexible schedule for the warehouse's operational work, and one dock would also be available for eventualities such as truck delays or the arrival of an extra truck. Table 1 summarizes the obtained results by using CPLEX and Gurobi.

When tests are performed for a future scenario with more trucks (one inbound and two outbound), the minimum makespan is 269.1 minutes with five or six docks. With four docks, the makespan increases to 315.2 minutes, 46 minutes longer than five docks, which might not be relevant. However, considering the opinion of experts, this is a considerable amount of time and is quite important because this difference determines whether workers have to stay an extra hour. Additionally, considering that 16 people work in the area of operations on this shift, the company could save the monthly salary of one worker only by avoiding an extra hour of B shift. With six docks, the makespan is the same as five; however, five docks would recommend this schedule since it leaves one dock available if there are any problems during the shift's operations. It is important to mention that the experts also point out that saving 45 minutes or more justifies using another dock for scheduling trucks because, according to the variability of this time in the schedule, it could easily result in an extra hour of work. Table 2 shows the results for the future scenario by using CPLEX and Gurobi. 
TABLE 1: Obtained results for the current B shift.

\begin{tabular}{|c|c|c|c|c|c|}
\hline & Number of platforms & Makespan (min) & Lower bound (min) & Gap (\%) & CPU time (sec) \\
\hline \multirow{6}{*}{ CPLEX } & 1 & 1034.3 & 691.6 & 33.13 & 9000.00 \\
\hline & 2 & 512.1 & 337.8 & 34.04 & 9000.00 \\
\hline & 3 & 338.1 & 254.1 & 21.89 & 9000.00 \\
\hline & 4 & 269.1 & 269.1 & 0.00 & 4.41 \\
\hline & 5 & 269.1 & 269.1 & 0.00 & 3.00 \\
\hline & 6 & 269.1 & 269.1 & 0.00 & 3.90 \\
\hline \multirow{6}{*}{ Gurobi } & 1 & 1034.3 & 756.44 & 26.86 & 9000.00 \\
\hline & 2 & 512.1 & 282.32 & 44.87 & 9000.00 \\
\hline & 3 & 338 & 269.1 & 20.38 & 9000.00 \\
\hline & 4 & 269.1 & 269.1 & 0.00 & 4.52 \\
\hline & 5 & 269.1 & 269.1 & 0.00 & 2.39 \\
\hline & 6 & 269.1 & 269.1 & 0.00 & 1.91 \\
\hline
\end{tabular}

Source: owner.

TABLE 2: Obtained results for the future scenario B shift.

\begin{tabular}{|c|c|c|c|c|c|}
\hline & Number of platforms & Makespan (min) & Lower bound (min) & Gap (\%) & CPU time (sec) \\
\hline \multirow{6}{*}{ CPLEX } & 1 & 1290.60 & 766.7 & 40.59 & 9000.00 \\
\hline & 2 & 640.2 & 312.17 & 51.24 & 9000.00 \\
\hline & 3 & 419 & 264.1 & 36.97 & 9000.00 \\
\hline & 4 & 315.2 & 264.1 & 16.21 & 9000.00 \\
\hline & 5 & 269.1 & 264.1 & 1.86 & 11.89 \\
\hline & 6 & 269.1 & 264.1 & 1.86 & 6.27 \\
\hline \multirow{6}{*}{ Gurobi } & 1 & 1290.60 & 815.2 & 36.80 & 5331.00 \\
\hline & 2 & 640.2 & 279.1 & 56.40 & 9000.20 \\
\hline & 3 & 418.52 & 267.02 & 36.20 & 9000.20 \\
\hline & 4 & 315.4 & 269.1 & 14.68 & 9000.20 \\
\hline & 5 & 269.1 & 265.49 & 1.34 & 15.8 \\
\hline & 6 & 269.1 & 268.95 & 0.05 & 7.53 \\
\hline
\end{tabular}

Source: owner.

3.2.3. C Shift Results. For the current scenario, the instances evaluated include all trucks assigned to any of the three docks (instance 1), sharing docks 2 and 3 (instance 2), and each product category with its corresponding docks (instance 3 ). After the results were obtained, instance 3 was discarded because its makespan exceeds the available time in a shift. Instance 1 has a makespan three minutes shorter than instance 2. The latter is chosen because it prevents refrigerated products from being shipped from dock 1 (instance 1 ), which is the farthest from the Refrigerated chamber, and so the product travel time is more significant. However, the travel time of Refrigerated products should be minimized because having the product outside the recommended environment or in transit for a long time should be avoided not to break the cold chain. Instance 2 also allows a lesser crossover of products, fewer temperature changes for workers walking with products through the two chambers, and fewer errors in the transfer from trucks to warehouses and vice versa. In the results of instance 2 , outbound trucks with Refrigerated and RCC products depart right at their time limit of 360 minutes after operations start, and the last Ice Cream trucks depart only 12 minutes later. For this reason, it is recommended to prioritize Refrigerated and RCC trucks since Ice Cream trucks, according to the schedule, have 50 more minutes of slack time to be dispatched within the shift. Table 3 shows the obtained results for the current scenario of the $\mathrm{C}$ shift.

For a future scenario with the new arrangement of the Ice Cream and Refrigerated chambers, both categories see benefits. In the previous case, when the Refrigerated chamber only had one exclusive dock and used one dock from the Ice Cream chamber, trucks departed right at the time limit, which was at six hours of operations or 360 minutes. With the new chambers, there are three docks available only for the Refrigerated category and RCC subcategory, letting the makespan decrease by 81.7 minutes for a total of 278.3 minutes, which is enough time to dispatch all trucks in this category before the time limit and without pressing the operations. The makespan of the Ice Cream category also decreases thanks to having two exclusive docks. In the previous case, the last trucks were dispatched in 372.5 minutes; with the new chambers, the makespan decreases by almost two hours, for a minimum makespan of 253.9 minutes.

The main benefit for both categories is makespan reduction since operation time decreases considerably in both. For the company, this also means not paying overtime because, considering that 21 people work on the $\mathrm{C}$ shift, just by not asking workers to stay over two hours (which can be saved with this new schedule), the company could save two 
TABLE 3: Obtained results for the current $\mathrm{C}$ shift.

\begin{tabular}{|c|c|c|c|c|c|}
\hline & Instance & Makespan (min) & Lower bound (min) & Gap (\%) & CPU time (sec) \\
\hline \multirow{3}{*}{ CPLEX } & 1 & 369.3 & 160.9 & 56.43 & 9000.00 \\
\hline & 2 & 372.5 & 180.49 & 51.55 & 9000.00 \\
\hline & 3 & 594.2 & 351.23 & 40.89 & 9000.00 \\
\hline \multirow{3}{*}{ Gurobi } & 1 & 367.47 & 161.08 & 56.16 & 9000.00 \\
\hline & 2 & 370.5 & 198.3 & 46.48 & 9000.00 \\
\hline & 3 & 594.2 & 422.3 & 28.93 & 9000.00 \\
\hline
\end{tabular}

Source: owner.

TABLE 4: Obtained results for the future scenario of ice cream in C shift.

\begin{tabular}{|c|c|c|c|c|c|}
\hline & Number of platforms & Makespan (min) & Lower bound (min) & Gap (\%) & CPU time (sec) \\
\hline \multirow{13}{*}{ CPLEX } & 1 & 737.00 & 442.57 & 39.95 & 9000.00 \\
\hline & 2 & 363.90 & 249.10 & 31.55 & 9000.00 \\
\hline & 3 & 263.90 & 245.10 & 7.12 & 9000.00 \\
\hline & 4 & 245.10 & 245.10 & 0.00 & 1.26 \\
\hline & 5 & 245.10 & 245.10 & 0.00 & 1.74 \\
\hline & 6 & 245.10 & 245.10 & 0.00 & 1.69 \\
\hline & 7 & 245.10 & 245.10 & 0.00 & 1.86 \\
\hline & 9 & 245.10 & 245.10 & 0.00 & 3.16 \\
\hline & 12 & 245.10 & 245.10 & 0.00 & 3.03 \\
\hline & 15 & 245.10 & 245.10 & 0.00 & 4.56 \\
\hline & 18 & 245.10 & 245.10 & 0.00 & 5.1 \\
\hline & 19 & 245.10 & 245.10 & 0.00 & 5.7 \\
\hline & 21 & 245.10 & 245.10 & 0.00 & 11.29 \\
\hline \multirow{13}{*}{ Gurobi } & 1 & 737.00 & 515.40 & 30.07 & 9000.00 \\
\hline & 2 & 363.90 & 245.10 & 32.65 & 9000.00 \\
\hline & 3 & 264.30 & 245.10 & 7.26 & 9000.00 \\
\hline & 4 & 245.10 & 245.10 & 0.00 & 1.74 \\
\hline & 5 & 245.10 & 245.10 & 0.00 & 3.25 \\
\hline & 6 & 245.10 & 245.10 & 0.00 & 1.03 \\
\hline & 7 & 245.10 & 245.10 & 0.00 & 2.13 \\
\hline & 9 & 245.10 & 245.10 & 0.00 & 3.35 \\
\hline & 12 & 245.10 & 245.10 & 0.00 & 4.78 \\
\hline & 15 & 245.10 & 245.10 & 0.00 & 5.37 \\
\hline & 18 & 245.10 & 245.10 & 0.00 & 5.13 \\
\hline & 19 & 245.10 & 245.10 & 0.00 & 10.4 \\
\hline & 21 & 245.10 & 245.10 & 0.00 & 8.01 \\
\hline
\end{tabular}

Source: owner.

to three times the monthly salary of a worker each time $\mathrm{C}$ shift does not work overtime. Finally, the improved schedules for both shifts reduce the makespan, prevent sending trucks "on tour," and reduce delay fees paid by the IDC to transport companies. Tables 4 and 5 summarize the future scenario for C Shift.

\section{Concluding Remarks and Future Directions}

The problem solved is associated with a cross-docking system, focused on the trucks' scheduling, excluding the warehouse's internal operational tasks. The scheduling minimizes the total operating time, ranging from when the first truck enters until the last dispatch truck leaves, also known as "makespan." The results obtained make it possible to minimize the trucks' waiting on the platforms by providing a supply and dispatch schedule. This approach considers the questions "where? and when?" schedule of each truck, in other words, "which platform and at what time" each truck should enter and exit. The model's execution time is reasonable; therefore, it is possible to implement solutions or make changes to eventualities in the same shift.

This paper proposed a MILP model to solve the scheduling problem of inbound and outbound trucks of a cross-docking platform, with makespan minimization. The model has been tested with actual data obtained from a multinational food company in Concepción, Chile, under different scenarios. The model was run using the solvers CPLEX and Gurobi.

The results obtained in the $\mathrm{B}$ shift instance establish that the company's best schedule involves using five of the six docks available and leaving one for any eventuality. The main benefits will be reflected in a decrease in the monthly overtime of that shift, representing savings equivalent to one worker's monthly salary for every overtime hour that the 
TABLE 5: Obtained results for the future scenario of refrigerated products in $\mathrm{C}$ shift.

\begin{tabular}{|c|c|c|c|c|}
\hline Number of platforms & Makespan (min) & Lower bound (min) & Gap (\%) & CPU time (sec) \\
\hline 1 & 1033.10 & 691.85 & 33.03 & 9000.00 \\
\hline 2 & 511.70 & 313.96 & 38.64 & 9000.00 \\
\hline 3 & 380.90 & 295.90 & 22.32 & 9000.00 \\
\hline 4 & 315.10 & 295.90 & 6.09 & 9000.00 \\
\hline 5 & 295.90 & 295.90 & 0.00 & 3.5 \\
\hline 6 & 295.90 & 295.90 & 0.00 & 3.83 \\
\hline 7 & 295.90 & 295.90 & 0.00 & 2.06 \\
\hline 9 & 295.90 & 295.90 & 0.00 & 2.46 \\
\hline 12 & 295.90 & 295.90 & 0.00 & 5.14 \\
\hline 15 & 295.90 & 295.90 & 0.00 & 3.11 \\
\hline 18 & 295.90 & 295.90 & 0.00 & 5.13 \\
\hline 21 & 295.90 & 295.90 & 0.00 & 10.67 \\
\hline 1 & 1033.10 & 760.00 & 26.40 & 970 \\
\hline 2 & 511.70 & 297.77 & 41.81 & 9000.00 \\
\hline 3 & 381.70 & 295.90 & 22.47 & 9000.00 \\
\hline 4 & 315.90 & 295.90 & 6.33 & 9000.00 \\
\hline 5 & 295.90 & 295.90 & 0.00 & 3.16 \\
\hline 6 & 295.90 & 295.90 & 0.00 & 3.05 \\
\hline 7 & 295.90 & 295.90 & 0.00 & 3.37 \\
\hline 9 & 295.90 & 295.90 & 0.00 & 4.14 \\
\hline 12 & 295.90 & 295.90 & 0.00 & 10.27 \\
\hline 15 & 295.90 & 295.90 & 0.00 & 18.25 \\
\hline 18 & 295.90 & 295.90 & 0.00 & 23.14 \\
\hline 21 & 295.90 & 295.90 & 0.00 & 30.83 \\
\hline
\end{tabular}

Source: owner.

shift does not run. The $\mathrm{C}$ shift results show that the new Ice Cream chamber will bring significant savings in operating times. The benefits of this new schedule could also be reflected in decreased overtime.

Regarding the model, solvers CPLEX and Gurobi deliver equal values for the objective function and find optimal solutions in a few seconds; when the problem becomes more complex, both solvers find feasible solutions close to the lower limit in less than 2.5 hours. Finally, based on the factor analysis results, it is recommended that products be received in equal distributions among all inbound trucks in general terms. This fact is an effort performed to load all outbound trucks equally; in each of the trucks, there should be no more than three different types of products if they have different characteristics; and lastly, the number of docks used justifies the total operating time (makespan).

As future work, we suggest extending this research by incorporating all the warehouse tasks, such as order picking and the vehicle routing problem. Also, stochastic considerations must be incorporated into the proposed model. Solution strategies for the stochastic model such as Scenarios [43, 44] or Sample Average Approximation [45, 46] must be applied. Similarly, a heuristic method can be developed to solve problems with larger-scale instances and compare these with the results obtained in this paper.

\section{Data Availability}

The instance data used to support the findings of this study is available by e-mail to the corresponding author.

\section{Conflicts of Interest}

The authors declare that there are no conflicts of interest regarding the publication of this paper.

\section{Acknowledgments}

This work has been partially supported by Universidad del Bío-Bío through the project 2060222 IF/R and Universidad del Valle, Colombia. This support is gratefully acknowledged.

\section{References}

[1] C.-S. Lu, "Market segment evaluation and international distribution centers," Transportation Research Part E: Logistics and Transportation Review, vol. 39, no. 1, pp. 49-60, 2003.

[2] B. Schaffer, "Implementing a successful crossdocking operation," IIE Solutions, vol. 29, no. 10, pp. 34-36, 1997.

[3] M. R. Galbreth, J. A. Hill, and S. Handley, "An investigation of the value of cross-docking for supply chain management," Journal of Business Logistics, vol. 29, no. 1, pp. 225-239, 2008.

[4] N. Boysen and M. Fliedner, "Cross dock scheduling: classification, literature review and research agenda," Omega, vol. 38, no. 6, pp. 413-422, 2010.

[5] D. Buakum and W. Wisittipanich, "A literature review and further research direction in cross-docking," in Proceedings of the International Conference on Industrial Engineering and Operations Management, pp. 471-481, Toronto, Canada, October 2019.

[6] R. K. Mavi, M. Goh, N. K. Mavi et al., "Cross-docking: a systematic literature review," Sustainability, vol. 12, no. 11, p. $4789,2020$. 
[7] M. M. Nasiri, A. Rahbari, F. Werner, and R. Karimi, "Incorporating supplier selection and order allocation into the vehicle routing and multi-cross-dock scheduling problem," International Journal of Production Research, vol. 56, no. 19, pp. 6527-6552, 2018.

[8] A. B. Arabani, S. F. Ghomi, and M. Zandieh, "A multi-criteria cross-docking scheduling with just-in-time approach," The International Journal of Advanced Manufacturing Technology, vol. 49, no. 5-8, pp. 741-756, 2010.

[9] Y. Li, A. Lim, and B. Rodrigues, "Crossdocking-JIT scheduling with time windows," Journal of the Operational Research Society, vol. 55, no. 12, pp. 1342-1351, 2004.

[10] U. M. Apte and S. Viswanathan, "Effective cross docking for improving distribution efficiencies," International Journal of Logistics Research and Applications, vol. 3, no. 3, pp. 291-302, 2000.

[11] H. Arbabi, M. M. Nasiri, and A. Bozorgi-Amiri, "A hub-andspoke architecture for a parcel delivery system using the crossdocking distribution strategy," Engineering Optimization, vol. 1, pp. 1-20, 2020.

[12] M. Gümüş and J. H. Bookbinder, "Cross-docking and its implications in location-distribution systems," Journal of Business Logistics, vol. 25, no. 2, pp. 199-228, 2004.

[13] J. Van Belle, P. Valckenaers, and D. Cattrysse, "Cross-docking: state of the art," Omega, vol. 40, no. 6, pp. 827-846, 2012.

[14] P. Buijs, I. F. A. Vis, and H. J. Carlo, "Synchronization in cross-docking networks: a research classification and framework," European Journal of Operational Research, vol. 239, no. 3, pp. 593-608, 2014.

[15] M. Bachlaus, M. K. Pandey, C. Mahajan, R. Shankar, and M. K. Tiwari, "Designing an integrated multi-echelon agile supply chain network: a hybrid taguchi-particle swarm optimization approach," Journal of Intelligent Manufacturing, vol. 19, no. 6, p. 747, 2008.

[16] J. J. Bartholdi and K. R. Gue, "The best shape for a crossdock," Transportation Science, vol. 38, no. 2, pp. 235-244, 2004.

[17] Y. H. Lee, J. W. Jung, and K. M. Lee, "Vehicle routing scheduling for cross-docking in the supply chain," Computers \& Industrial Engineering, vol. 51, no. 2, pp. 247-256, 2006.

[18] C.-J. Liao, Y. Lin, and S. C. Shih, "Vehicle routing with crossdocking in the supply chain," Expert Systems with Applications, vol. 37, no. 10, pp. 6868-6873, 2010.

[19] L. Y. Tsui and C. H. Chang, "A microcomputer based decision support tool for assigning dock doors in freight yards," Computers \& Industrial Engineering, vol. 19, no. 1-4, pp. 309-312, 1990.

[20] A. Rahbari, M. M. Nasiri, F. Werner, M. Musavi, and F. Jolai, "The vehicle routing and scheduling problem with crossdocking for perishable products under uncertainty: two robust bi-objective models," Applied Mathematical Modelling, vol. 70, pp. 605-625, 2019.

[21] A. H. Goodarzi, R. Tavakkoli-Moghaddam, M. Amiri-Aref, and A. Amini, "A new bi-objective vehicle routing-scheduling problem with cross-docking: mathematical model and algorithms," Computers \& Industrial Engineering, vol. 149, Article ID 106832, 2020.

[22] H. Khorshidian, M. Akbarpour Shirazi, and S. M. T. Fatemi Ghomi, "An intelligent truck scheduling and transportation planning optimization model for product portfolio in a crossdock," Journal of Intelligent Manufacturing, vol. 30, no. 1, pp. 163-184, 2019.

[23] F. Chen and C.-Y. Lee, "Minimizing the makespan in a twomachine cross-docking flow shop problem," European Journal of Operational Research, vol. 193, no. 1, pp. 59-72, 2009.
[24] F. Chen and K. Song, "Minimizing makespan in two-stage hybrid cross docking scheduling problem," Computers \& Operations Research, vol. 36, no. 6, pp. 2066-2073, 2009.

[25] N. Boysen, M. Fliedner, and A. Scholl, "Scheduling inbound and outbound trucks at cross docking terminals," OR Spectrum, vol. 32, no. 1, pp. 135-161, 2010.

[26] C. R. Rosales, M. J. Fry, and R. Radhakrishnan, "Transfreight reduces costs and balances workload at Georgetown crossdock," Interfaces, vol. 39, no. 4, pp. 316-328, 2009.

[27] J. F. Wang and A. Regan, "Real-time trailer scheduling for crossdock operations," Transportation Journal, vol. 47, no. 2, pp. 5-20, 2008.

[28] D. Konur and M. M. Golias, "Analysis of different approaches to cross-dock truck scheduling with truck arrival time uncertainty," Computers \& Industrial Engineering, vol. 65, no. 4, pp. 663-672, 2013.

[29] N. Boysen, D. Briskorn, and M. Tschöke, "Truck scheduling in cross-docking terminals with fixed outbound departures," $O R$ Spectrum, vol. 35, no. 2, pp. 479-504, 2013.

[30] N. Boysen, "Truck scheduling at zero-inventory cross docking terminals," Computers \& Operations Research, vol. 37, no. 1, pp. 32-41, 2010.

[31] M. Shakeri, M. Y. H. Low, and Z. Li, "A generic model for crossdock truck scheduling and truck-to-door assignment problems," in Proceedings of the 6th IEEE International Conference on Industrial Informatics, pp. 857-864, Daejeon, Republic of Korea, July 2008.

[32] Z. P. Li, M. Y. H. Low, M. Shakeri, and Y. G. Lim, "Crossdocking planning and scheduling: problems and algorithms," SIMTech Technical Reports, vol. 10, no. 3, pp. 159-167, 2009.

[33] F. Enderer, C. Contardo, and I. Contreras, "Integrating dockdoor assignment and vehicle routing with cross-docking," Computers \& Operations Research, vol. 88, pp. 30-43, 2017.

[34] V.V. Thai, "Competencies required by port personnel in the new era: conceptual framework and case study," International Journal of Shipping and Transport Logistics, vol. 4, no. 1, p. 49, 2012.

[35] J. Saranen, B. Szekely, O. P. Hilmola, and T. Toikka, "Transportation strategy in international supply chains-the case of Russia," International Journal of Shipping and Transport Logistics, vol. 2, no. 2, pp. 168-186, 2010.

[36] W. Yu and P. J. Egbelu, "Scheduling of inbound and outbound trucks in cross docking systems with temporary storage," European Journal of Operational Research, vol. 184, no. 1, pp. 377-396, 2008.

[37] W. Yu, "Truck scheduling for cross docking systems with multiple receiving and shipping docks," International Journal of Shipping and Transport Logistics, vol. 7, no. 2, pp. 174-196, 2015.

[38] F. Heidari, S. H. Zegordi, and R. Tavakkoli-Moghaddam, "Modeling truck scheduling problem at a cross-dock facility through a bi-objective bi-level optimization approach," Journal of Intelligent Manufacturing, vol. 29, no. 5, pp. 1155-1170, 2018.

[39] A. Rijal, M. Bijvank, and R. De Koster, "Integrated scheduling and assignment of trucks at unit-load cross-dock terminals with mixed service mode dock doors," European Journal of Operational Research, vol. 278, no. 3, pp. 752-771, 2019.

[40] S. I. Sayed, I. Contreras, J. A. Diaz, and D. E. Luna, "Integrated cross-dock door assignment and truck scheduling with handling times," TOP: an Official Journal of the Spanish Society of Statistics and Operations Research, vol. 28, pp. 705-727, 2020.

[41] P. Guo, F. Weidinger, and N. Boysen, "Parallel machine scheduling with job synchronization to enable efficient 
material flows in hub terminals," Omega, vol. 89, pp. 110-121, 2019.

[42] A.-L. Ladier and G. Alpan, "Cross-docking operations: current research versus industry practice," Omega, vol. 62, pp. 145-162, 2016.

[43] J. W. Escobar, "Supply chain optimization with variable demand by considering financial criteria and scenarios," Revista Facultad de Ingeniería, vol. 26, no. 44, pp. 23-34, 2017.

[44] J. W. Escobar, A. A. Marin, and J. D. Lince, "Multi-objective mathematical model for the redesign of supply chains considering financial criteria optimisation and scenarios," International Journal of Mathematics in Operational Research, vol. 16, no. 2, pp. 238-256, 2020.

[45] J. C. Paz, J. A. Orozco, J. M. Salinas, N. C. Buriticá, and J. W. Escobar, "Redesign of a supply network by considering stochastic demand," International Journal of Industrial Engineering Computations, vol. 6, no. 4, pp. 521-538, 2015.

[46] D. N. Rodado, J. W. Escobar, R. G. García-Cáceres, and F. A. N. Atencio, "A mathematical model for the product mixing and lot-sizing problem by considering stochastic demand," International Journal of Industrial Engineering Computations, vol. 8, no. 2, pp. 237-250, 2017. 